\title{
Convergence of carbon dioxide performance across Swedish industrial sectors: An environmental index approach ${ }^{2}$
}

\author{
Runar Brännlund ${ }^{\text {a }}$, Tommy Lundgren ${ }^{\text {a }}$, Patrik Söderholm ${ }^{\text {b }}$ \\ a Centre for Environmental and Resource Economics (CERE), Umeå School of Business and Economics, Umeå University, Sweden \\ ${ }^{\mathrm{b}}$ Economics Unit, Luleå University of Technology, Sweden
}

\section{A R T I C L E I N F O}

\section{Article history:}

Received 19 December 2014

Received in revised form 5 May 2015

Accepted 4 July 2015

Available online 26 July 2015

JEL classification:

D22

Q01

Q40

Q48

Q54

Q56

Keywords:

Convergence

Carbon dioxide emission intensity

Industry

Sweden

\begin{abstract}
A B S T R A C T
The overall objective of the paper is to analyze convergence of $\mathrm{CO}_{2}$ emission intensity across manufacturing sectors in Sweden. Our approach differs from previous work on carbon convergence in that it employs a theoretical framework to construct a $\mathrm{CO}_{2}$ performance index, which explicitly takes into account that industrial firms produce good as well as bad outputs. This index is then used as the dependent variable in a growth-type regression equation. We employ a data set covering 14 industrial sectors over the time period 1990-2008. The results suggest the presence of conditional $\beta$-convergence in $\mathrm{CO}_{2}$ performance among the industrial sectors in Sweden. Moreover, the speed of convergence varies significantly in the sense that the higher the capital intensity is, the lower is the convergence rate to the different steady states. This is likely to reflect the importance of - and in part the costs associated with - capital turnover to achieve a transition towards lower $\mathrm{CO}_{2}$ emission paths.
\end{abstract}

(C) 2015 Published by Elsevier B.V.

\section{Introduction}

The objective of this paper is to empirically analyze carbon dioxide $\left(\mathrm{CO}_{2}\right)$ emission intensity convergence across manufacturing sectors in Sweden. The novelty here is basically that our approach has a natural underpinning based on existing production theory. As such it differs from the traditional environmental, or emission, convergence literature in the sense that we address the growth path of the (inverse) emission intensity. An important advantage with this approach is that it takes explicit account of the notion that firms produce good and bad outputs simultaneously. This is in contrast to the more commonly used growth path of emission approach, which ignores this multi-output property and, for instance, regresses the growth rate of $\mathrm{CO}_{2}$ emissions per capita on the initial (or lagged) level of emission per capita and the gross domestic product (GDP) (Pettersson et al., 2014).

Our empirical methodology can be described as a straightforward two-step approach; in the first step we calculate an environmental $\left(\mathrm{CO}_{2}\right)$ performance index for each industrial sector in each year. In the

it This research was generously funded by the Swedish Energy Agency. Constructive comments from three anonymous reviewers are gratefully acknowledged. Any remaining errors reside solely with the authors. second step we employ this index as the dependent variable in a growth-type regression equation.

The motivation for studying $\mathrm{CO}_{2}$ emissions convergence between industrial sectors within a single country is two-fold. First, it may provide knowledge of what one can expect concerning future convergence at the international level, and this may in turn have possible repercussions for the perceived fairness of various global climate policy burdensharing schemes (Pettersson et al., 2014). Previous research tests for $\mathrm{CO}_{2}$ emissions convergence among various countries, without however referring to the structural heterogeneity across these economies (see further Section 2). For instance, if different industry sectors are found to converge (conditionally) towards their steady-state levels, this would imply that countries with similar industry structures may be more likely to converge, while the opposite could hold for countries with heterogeneous industrial compositions. The presence of different industry structures may also influence the speed of emissions convergence, and in this paper we devote particular attention to the role of capital intensity. Moreover, since panel data usually are more detailed and reliable on the country level than aggregate data across countries, a within-country analysis may in many cases be preferable.

Second, a within-country analysis could be important and interesting on its own, especially concerning the consequences for different 
sectors of climate and energy policies. For instance, it may provide a possibility to study distributional issues, or burden sharing, within a country as a result of a global or national policy. A few previous studies on cross-country emission convergence (Brock and Taylor, 2010; Ordás Criado et al., 2011) outline theoretical models that predict convergence in per capita emissions, typically by extending the traditional Solow income growth model with, for instance, an emission abatement function. In this paper we make no attempt to provide a similar theoretical prediction of $\mathrm{CO}_{2}$ convergence across different industrial sectors in the same country. Our regression model permits a test of $\mathrm{CO}_{2}$ convergence, and we simply note that in our case convergence may arise due to different types of spillovers across sectors, both technological (e.g., improvements in the efficiency of fuel combustion technologies) as well as managerial (e.g., the use of environmental and energy management systems). Moreover, although different sectors may face different fossil fuel prices and tax levels, the domestic climate policy may also induce $\mathrm{CO}_{2}$ convergence across sectors even if some (capital-intensive) sectors experiencing slower rates of convergence than others and also possibly to different steady-state levels (relative convergence).

The case in our study is Sweden. The reason for this is also two-fold. Firstly, we have access to a unique and detailed panel data set for the Swedish industrial sectors, which facilitates an in-depth analysis of this kind. Specifically, we employ data across 14 industrial sectors over the time period 1990-2008. Secondly, Sweden has since a fairly long time had a very active climate and energy policy, including significant changes in carbon and energy taxes over time. The Swedish $\mathrm{CO}_{2}$ tax (including some deductions for energy-intensive industrial sectors) was introduced already in 1991. This policy context makes it interesting to analyze emission dynamics in Swedish industry sectors, and to relate it to changes in fuel prices, capital intensity, etc.

The remainder of the paper is structured as follows. In the next section we give a more detailed background and a view of the literature within the area of convergence of $\mathrm{CO}_{2}$ emissions. In Section 3 we go through the basic theoretical framework of our approach, whereas the empirical model and method are outlined in Section 4. The data we use in the study are presented and discussed in Section 5 , and the results from the analysis in Section 6. Finally, Section 7 is devoted to some concluding comments.

\section{Background to the $\mathrm{CO}_{2}$ convergence literature}

Several previous studies present evidence on $\mathrm{CO}_{2}$ convergence, and overall this work can be divided into two main categories: (a) a relatively rich empirical literature investigating convergence of $\mathrm{CO}_{2}$ emissions among countries worldwide has emerged (see Pettersson et al., 2014 for a recent literature review); and (b) a more limited set of studies addressing $\mathrm{CO}_{2}$ convergence across regions (e.g., Aldy, 2007; Baldwin and Sue Wing, 2013; Burnett, 2013; Huang and Meng, 2013; Zhao, 2014) as well as across sectors (e.g., Moutinho et al., 2014; Wang and Zhang, 2014) in one single country. The latter category has a strong emphasis on China and the USA. As was noted above, there could be important links between convergence at the international level and the emission dynamics at the country level, and in the remainder of this section we comment on both of these research streams and their interrelation.

The research on $\mathrm{CO}_{2}$ emissions convergence across countries has particularly addressed per capita emissions. An important reason for this focus is that convergence in per capita terms could influence the political economy of negotiating multilateral climate agreements (e.g., Aldy, 2006). The principle of allocating to each individual the same "right to pollute" has been endorsed by a number of national governments (typically in developing countries), non-governmental organizations, scholars etc. (e.g., Frankel, 2007; Mattoo and Subramanian, 2010). However, if per capita emissions cannot be expected to converge, this principle would result in substantial international transfers of rents through carbon allowance trading or the relocation of emission-intensive industries; many countries (i.e., not the least high emitters in the developed world) would then be unwilling to engage in a global climate commitment.

Methodologically, the empirical carbon convergence research can roughly be divided into three different concepts: beta $(\beta)$, sigma $(\sigma)$ and stochastic convergence. These can in turn be divided into conditional (relative) and unconditional (absolute) convergence. $\beta$ convergence follows from the neoclassical economic growth literature (e.g., Solow, 1956), and implies that countries with lower initial emission levels will experience higher emissions growth levels and hence "catch-up" with the higher-emission countries. Moreover, absolute $\beta$ convergence implies that all countries exhibit the same steady-state level of emissions, while the relative counterpart means that the growth paths differ and thus do not converge to the same level. $\beta$-convergence of $\mathrm{CO}_{2}$ emissions has been addressed in a few previous studies (e.g., Brock and Taylor, 2010; Strazicich and List, 2003; Van Nguyen, 2005). Over time increased attention has also been devoted to other convergence concepts such as $\sigma$-convergence, which translates into a decrease over time in the cross-section variance of per capita emissions (e.g., Aldy, 2006; Camarero et al., 2013; Panopoulou and Pantelidis, 2009). This approach has in turn led to the use of non-parametric testing procedures taking into account the dynamics of the full distribution of countries. The distributional dynamics approach follows Quah (1993), and has been applied empirically to $\mathrm{CO}_{2}$ emissions across countries in, for instance, Van Nguyen (2005), Ezcurra (2007) and Ordás Criado et al. (2011). Finally, stochastic convergence implies that shocks to per capita emissions for one country relative to another (or the average of the sample) are temporary. This is investigated seeking for stationarity using different types of unit root tests (e.g., Barassi et al., 2008; Nourry, 2009; Westerlund and Basher, 2008; Yavuz and Yilanci, 2013).

The results from the above research stream have been sensitive to the econometric approach used and the data set employed (e.g., the length of the time series, geographical coverage etc.). Overall, though, the research shows some evidence of $\mathrm{CO}_{2}$ convergence between developed (i.e., OECD) countries but divergence at the global level. One reason for this latter result could be that countries differ significantly in terms of fossil fuel reserves, fuels which historically have been relatively costly to transport over long distances (e.g., coal, natural gas etc.). The fact that different subsets of countries yield different results (e.g., convergence among OECD countries) could be due to countries mimicking each other's climate policies (e.g., following many countries' ratification of the Kyoto Protocol). Another possible reason may be differences in industrial and institutional structures, and since such structures are changing very slowly non-convergence is not unlikely, given the relative short time spans in the studies. Related to this is also the speed, or rate, of convergence; even if countries' or different economic sectors' emissions converge this may take a very long time making the adjustment towards climate stabilization more difficult. For instance, the capital stock of the economy is durable and replacing industrial equipment, buildings, and infra-structure is likely to be relatively costly and a time-consuming process.

As pointed out by Pettersson et al. (2014), the $\mathrm{CO}_{2}$ convergence research addressing cross-country patterns has so far devoted little attention to the underlying explanations to different emission growth paths, including the role of public policy measures and industrial structure (see also Never and Betx, 2014). The distribution of $\mathrm{CO}_{2}$ emissions is strongly related to the structure of a country's economy, and this hinges on that country's natural endowments (e.g., fossil fuel reserves), development level and its comparative advantage in the production of various goods. All these conditions, in turn, are not preset requirements, but depend on the individual decisions of households, firms and governments.

As was noted above, a few recent studies have addressed $\mathrm{CO}_{2}$ convergence patterns across regions and sectors in single countries, thus providing complementing knowledge on country-specific emission dynamics. The majority of this work focuses on convergence of $\mathrm{CO}_{2}$ 
emission intensities rather than per capita emissions. In this paper we investigate the role of industry structure, and we employ the $\beta$ convergence approach to test whether different industry sectors in Sweden converge in terms of their $\mathrm{CO}_{2}$ performance (intensity). Our work relates most strongly to the study by Moutinho et al. (2014), which addresses convergence of $\mathrm{CO}_{2}$ intensity across different energy and industrial sectors in Portugal. ${ }^{1}$ Wang and Zhang (2014) also investigate $\mathrm{CO}_{2}$ emissions in different sectors, but they focus on convergence within the same sectors across regions (in China).

In contrast to this research, and as noted above, our approach follows directly from an axiomatic representation of the production process taking into account that good and bad outputs are produced simultaneously. This representation can also be generalized to cases with several (good and bad) outputs, although in this paper we stick to the simple case of one bad output ( $\mathrm{CO}_{2}$ emissions) and one good output (industrial production in terms of value of sales). This provides a unit-independent measure of carbon performance. In addition, we investigate some key determinants of carbon performance, including the role of fuel prices, participation in emissions trading, capital intensity etc. The speed of $\mathrm{CO}_{2}$ convergence, including the role of capital intensity, is also addressed empirically.

\section{Theory and method}

The theoretical approach outlined here follows primarily Färe et al. (2006) and Färe et al. (2003). ${ }^{2}$ The theory is thus not novel, and the presentation in this section is motivated mainly as to make the reader aware of the basic underpinnings of the $\mathrm{CO}_{2}$ performance index that will be used in the empirical analysis.

The environmental performance index, $E P$, we derive is based on neoclassical production theory. In particular this means that we will use a quantity approach based on ratios of output distance functions. It turns out that in the specific case of one good and one bad output this ratio of distance functions boils down to a very simple expression showing the growth path of the inverse of the emission intensity.

The distance functions are defined on the output possibility set, $P(x)$, expressed as $P(x)=\{(y, b): x$ can produce $(y, b)\}$. Here $y$ is good output, $b$ is bad output, and $x$ is a vector of inputs. In general, $y$ and $b$ are also vectors. $P(x)$ is assumed to be convex, closed, and bounded, i.e., compact, with inputs and good outputs being freely disposable. Good outputs being freely disposable are formally expressed as $(y, b) \in P(x)$ and $y^{\prime} \leq y$ then $\left(y^{\prime}, b\right) \in P(x)$, which means that one good output can always be reduced without reducing any other output.

In addition to these technological properties, shaping the frontier of $P(x)$, it is assumed that outputs are weakly disposable, and that $(y, b)$ is null-joint, i.e., good output cannot be produced without producing any bad output.

Given the technological properties above and letting $x^{\circ}, b^{\circ}$, and $y^{\circ}$ be given reference levels of inputs, and bad and good outputs, respectively, a good and bad output quantity index can be specified. In the single good and bad output case these quantity indexes become ${ }^{3}$ :

$Q_{y}^{t}\left(y^{t+1}, y^{t}\right)=\frac{y^{t+1}}{y^{t}}$

\footnotetext{
${ }^{1}$ Miketa and Mulder (2005), Mulder and de Groot (2012) and Liddle (2009) analyze energy productivity and intensity (including convergence patterns) across different industrial sectors.

${ }^{2}$ An application of this particular approach using Swedish firm level data from 1990 to 2004, in a different context, can be found in Brännlund et al. (2014) and Lundgren and Marklund (forthcoming).

${ }^{3}$ If we have more than one good output and more than one bad output the quantity indexes will no longer be independent of $b^{\circ}, y^{\circ}$, and $x^{\circ}$. Färe et al. (2006) or Brännlund et al. (2014) for details.
}

$Q_{b}^{t}\left(b^{t+1}, b^{t}\right)=\frac{b^{t+1}}{b^{t}}$

The good output index in (1) reflects then the change in good output from period $t$ to period $t+1$, holding inputs and bad output constant, and similarly the index in (2) reflects the change in bad output, holding inputs and the good output constant.

Then, from (1) and (2) above, we can specify our environmental performance index, $E P$, as:

$E P^{t, t+1}\left(y^{t+1}, y^{t}, b^{t+1}, b^{t}\right)=\frac{Q_{y}^{t}\left(y^{t+1}, y^{t}\right)}{Q_{b}^{t}\left(b^{t+1}, b^{t}\right)}=\frac{y^{t+1} / y^{t}}{b^{t+1} / b^{t}}=\frac{y^{t+1} / b^{t+1}}{y^{t} / b^{t}}$,

which credits good output per unit of the bad output. Then, if production of the good (bad) output increases between the time periods $t$ and $t+1$, holding everything else constant, it will influence $E P^{t, t}+1$ positively (negatively).

From Eq. (3) it also clear that EP is the growth rate (plus one) of the inverse of the emission intensity index. That is, if we define the inverse to the emission intensity as $I^{t}=y^{t} / b^{t}$, then we have:

$I^{t}=E P^{t-1, t} \cdot I^{t-1}$

Or

$I^{t}=\prod_{i=1}^{t} E P^{i-1, i} \cdot I^{0}$

Dividing both sides of Eq. (5) with $I^{0}$ gives us then the accumulated environmental performance between time period 0 and $t$.

From Eq. (3) it is clear that EP can be decomposed into two components. For instance, if an industry's EP improves it can be investigated whether this is mainly due to an increase in the good output or mainly due to a reduction in the bad output, or due to a balanced combination of the two.

Finally, we can also study environmental performance at the aggregate industrial level by aggregating over the different sectors. As shown in Färe et al. (2006), environmental performance in the industry as a whole can be defined by a geometric mean of sector performances. We obtain:

$$
\begin{aligned}
\left(\prod_{i=1}^{I} \frac{y_{i, j}^{t+1} / b_{i, j}^{t+1}}{y_{i, j}^{t} / b_{i, j}^{t}}\right)^{1 / I} & =\frac{\left(\prod_{i=1}^{I} y_{i, j}^{t+1}\right)^{1 / I} /\left(\prod_{i=1}^{I} y_{i, j}^{t}\right)^{1 / I}}{\left(\prod_{i=1}^{I} b_{i, j}^{t+1}\right)^{1 / I} /\left(\prod_{i=1}^{I} b_{i, j}^{t}\right)^{1 / I}} \\
& =\frac{\left(\prod_{i=1}^{I} y_{i, j}^{t+1}\right)^{1 / I} /\left(\prod_{i=1}^{I} b_{i, j}^{t+1}\right)^{1 / I}}{\left(\prod_{i=1}^{I} y_{i, j}^{t}\right)^{1 / I} /\left(\prod_{i=1}^{I} b_{i, j}^{t}\right)^{1 / I}} .
\end{aligned}
$$

The fundamentals for our empirical analysis are Eqs. (3) and (5). Given data on good and bad outputs, we can calculate EP and $I$ to be used in the second step, the convergence analysis.

\section{Empirical approach}

The empirical analysis is performed in two steps. First, we calculate the $E P$ index at the industrial sector level based on $\mathrm{CO}_{2}$ emissions data and the theoretical underpinnings outlined above. In the second step we specify a typical $\beta$-convergence equation with $E P$ as the dependent variable and (lagged) I as one of the independent variables. Specifically, we focus on the so-called catch-up hypothesis by analyzing cross-sector convergence of environmental performance, or $\mathrm{CO}_{2}$-intensity, in terms of its growth rates (i.e., $\beta$-convergence). We employ panel data for 
Swedish manufacturing, and regress environmental performance, $E P$, on initial (inverse) $\mathrm{CO}_{2}$ emission intensity levels, I. Formally the empirical specification of our model can be written as:

$$
\ln E P_{i}^{t}=\alpha_{i}+\beta \ln I_{i}^{t-1}+\boldsymbol{\gamma} \mathbf{X}_{i}^{t}+\varepsilon_{i}^{t}, i=1, \ldots, N=\text { sectors }, t=1, \ldots,
$$$$
T=\text { time periods, }
$$

where $\beta$, the convergence parameter, is the parameter of our central interest. ${ }^{4} \mathrm{~A}$ negative $\beta$ indicates the existence of so-called $\beta$ convergence, suggesting that sectors with relatively low initial intensity levels catch up to the sectors with initially high levels. As was noted in the introduction, $\mathrm{CO}_{2}$ convergence may arise because the lowperforming sectors can benefit from the experiences developed and used by the high-performers. These experiences can concern both technology choices (e.g., the diffusion of energy-efficient fuel combustion technologies) as well as various management strategies (e.g., the use of environmental and energy management systems etc.). In addition, the domestic climate policy is overall fairly uniform, thus potentially inducing convergence in $\mathrm{CO}_{2}$ performance across sectors.

In Eq. (7), $\mathbf{X}$ is a vector of sector-specific variables with corresponding parameter vector $\boldsymbol{\gamma}$, and $\alpha_{i}$ represents sector-specific constants (i.e., unspecified fixed effects). Thus, if $\alpha_{i}=\alpha$ for all $i$, and $\boldsymbol{\gamma}=0$, then we have absolute convergence, i.e., all sectors converge to the same steady-state emission intensity level. If the above does not hold, though, we have conditional convergence, which means that the emission growth paths differ and do not converge to the same (absolute) emission intensity level.

The specification in Eq. (7) can be generalized further by allowing $\beta$ to vary between sectors. This would mean that we allow the speed of convergence to vary. To account for this we introduce interaction effects, and specify the following model:

$$
\ln E P_{i}^{t}=\alpha_{i}+\beta \ln I_{i}^{t-1}+\boldsymbol{\mu} t_{i}^{t-1} \mathbf{X}_{i}^{t}+\boldsymbol{\gamma} \mathbf{X}_{i}^{t}+\varepsilon_{i}^{t},
$$

where $\boldsymbol{\mu}$ is the vector of interaction parameters. Without these interaction terms $\beta$ represents an average over all sectors, alternatively it assumes that there is no heterogeneity over sectors. Allowing for heterogeneity or that $\beta$ depends on sector characteristics, is simply a more general model specification. For instance, a reasonable hypothesis is that capital-intensive industrial sectors will have a lower $\beta$, and thus lower speed of convergence, than the less capital-intensive sectors.

For our purposes the $\mathbf{X}$ vector consists of three variables; the average (weighted) price of fossil fuels, capital intensity, and a variable addressing whether a specific share of the firms in each sector is part of the European Emission Trading Scheme (EU ETS). All of these variables may potentially have significant impacts on the growth paths of emission intensity. The hypothesis that the EPs have been affected by the cost of using fossil fuels, and hence the price of fossil fuels, is plausible. Although the variation over sectors of each specific fossil fuel price is fairly small, the corresponding variation for the average fossil fuel price is sometimes considerable since the mix of fuels used differs between sectors and has changed over time (see further section). We anticipate that a higher fossil fuel price will induce the industry to improve $\mathrm{CO}_{2}$ performance.

Furthermore, we include a variable that reflects the capital intensity of each industry sector over the period. One could argue that capital-intensive sectors have more difficulties decreasing its $\mathrm{CO}_{2}$ emissions due to the often substantial energy amounts that are needed to run a large capital stock. On the other hand, sectors with high capital intensity may also be more motivated to save energy, and therefore invest relatively more in "green" and energy-saving

\footnotetext{
${ }^{4}$ One should note that this is a year-to-year, panel data specification of convergence. An alternative would be to specify a cross-sectional model that relates the mean of the environmental performance index over a time period to an initial time period intensity level. However, in our case, that reduces the data set to a point where estimation would be difficult to perform.
}

technology. If so, $E P$ would rather improve relative to less capitalintensive sectors. How capital intensity affects $E P$ is thus ultimately an empirical question.

The EU ETS was introduced in 2005. There is a large heterogeneity both within and between industry sectors whether these are included or not in this $\mathrm{CO}_{2}$ allowance scheme. To control for this we include a dummy variable, which takes the value of one (1) if more than $10 \%$ of the firms within a sector belongs to EU ETS at any given time period, and zero (0) otherwise. There are of course a number of other variables that may affect the growth paths of $\mathrm{CO}_{2}$ emission intensity, and some of these will be captured in the sector-specific fixed effects.

\section{Data definitions and sources}

The data used in this study have been drawn from a panel data set covering 14 Swedish manufacturing sectors over the time period 1990-2008 (SNI10-SNI37). ${ }^{5}$ This means that we have a total of 266 observations. In this particular application we use data on output, $y$ (value of sales divided by a sector-specific producer price index), $\mathrm{CO}_{2}$ emissions, $b$, capital intensity (the real value of the capital stock divided by the number of employees), $k$, fossil fuel price (i.e., a weighted average price of all used fossil fuels), $p$, and the share of firms within each sector that is part of EU ETS, ETS. The data on emissions only include the $\mathrm{CO}_{2}$ emissions following from direct fuel use at the company level (excluding the use of biofuels). Thus, in our case the emissions from the electricity sector have not been allocated to other sectors. In the Swedish case the latter would in fact not have made much of a difference since the country's electricity generation sector is more or less fossil fuel free. ${ }^{6}$

The means and the standard deviations of the above variables for each sector over the entire time period are presented in Table 1, whereas the box-plots in Figs. 1-2 show how the median and the variation between sectors of good and bad outputs have developed over time.

From Table 1 it is obvious that there is a substantial variation in the data across sectors and/or over time. For instance, the $\mathrm{CO}_{2}$ emissions range from very low in sectors such as printing, fabricated metals and rubber/plastic to considerably higher levels in pulp and paper, mining and iron and steel. The prices paid for fossil fuels also vary across the industry sectors. The main reason for this variation is that the mix of fossil fuels differs substantially across sectors.

The box-plots in Figs. 1 and 2 display the median and the variation in good and bad output in each year, i.e., between sectors. The height of each box is the difference between the 75th and 25th percentiles, while the horizontal line within each box represents the median. Concerning industrial output we see a clear upward trend, but at the same time an increase over time in the variation between sectors. This means that during the period the Swedish manufacturing industry experienced considerable structural changes. At the same time, the median $\mathrm{CO}_{2}$ emissions display a modest negative trend, especially since the early 2000s. However, we also see that the distribution tends to become more skewed and "compact" over time. Overall Figs. 1 and 2 indicate that the Swedish industry as an aggregate has improved its $\mathrm{CO}_{2}$ performance, i.e., more is produced with fewer emissions. ${ }^{7}$ Another way to put it is that there appears to have been absolute decoupling in the aggregate Swedish manufacturing industry.

\footnotetext{
${ }^{5}$ This data set in part emanates from Statistics Sweden industrial statistics. It has been used in other studies addressing related although different topics. For a more detailed description of the variables included, see Brännlund et al. (2014) or Färe et al. (2014) as well as the references therein.

${ }^{6}$ For the $\mathrm{CO}_{2}$ emissions we have had to exclude the emissions from coal used as input in the production process in the steel industry. The reason for this is that there have been major changes in the classification system over time, and this shows up as discrete shifts in coal use for some industries, especially the steel industry.

7 This corroborates the results and conclusions of Brännlund et al. (2014) using data up until the year 2004 at firm level.
} 
Table 1

Swedish manufacturing data: descriptive statistics, annual mean values 1990-2008 (standard deviations within parentheses). Base year 1990.

\begin{tabular}{|c|c|c|c|c|c|c|}
\hline Description & $N$ & Output MSEK & $\mathrm{CO}_{2}$ thousand tons & Price fuel SEK/kwh & ETS share* & Capital intensity SEK \\
\hline Manufacturing (total) & 266 & $\begin{array}{l}46,629 \\
(46,576)\end{array}$ & $\begin{array}{l}350 \\
(457)\end{array}$ & $\begin{array}{l}0.26 \\
(0.18)\end{array}$ & $\begin{array}{l}0.08 \\
(0.12)\end{array}$ & $\begin{array}{l}1206 \\
(1361)\end{array}$ \\
\hline Mining & 19 & $\begin{array}{l}11,156 \\
(1641)\end{array}$ & $\begin{array}{l}188 \\
(39)\end{array}$ & $\begin{array}{l}0.14 \\
(0.05)\end{array}$ & $0.08(0.00)$ & $\begin{array}{l}2676 \\
(1670)\end{array}$ \\
\hline Food & 19 & $\begin{array}{l}89,339 \\
(4525)\end{array}$ & $\begin{array}{l}636 \\
(87)\end{array}$ & $\begin{array}{l}0.26 \\
(0.12)\end{array}$ & $\begin{array}{l}0.02 \\
(0.00)\end{array}$ & $\begin{array}{l}807 \\
(381)\end{array}$ \\
\hline Textile & 19 & $\begin{array}{l}5038 \\
(1188)\end{array}$ & $\begin{array}{l}79 \\
(22)\end{array}$ & $\begin{array}{l}0.30 \\
(0.13)\end{array}$ & $\begin{array}{l}0 \\
(0)\end{array}$ & $\begin{array}{l}451 \\
(192)\end{array}$ \\
\hline Wood & 19 & $\begin{array}{l}36,721 \\
(11,908)\end{array}$ & $\begin{array}{l}73 \\
(15)\end{array}$ & $\begin{array}{l}0.36 \\
(0.17)\end{array}$ & $\begin{array}{l}0.03 \\
(0.00)\end{array}$ & $\begin{array}{l}824 \\
(220)\end{array}$ \\
\hline Pulp/paper & 19 & $\begin{array}{l}77,099 \\
(10,062)\end{array}$ & $\begin{array}{l}1459 \\
(417)\end{array}$ & $\begin{array}{l}0.19 \\
(0.09)\end{array}$ & $\begin{array}{l}0.47 \\
(0.01)\end{array}$ & $\begin{array}{l}2484 \\
(618)\end{array}$ \\
\hline Printing & 19 & $\begin{array}{l}5295 \\
(2540)\end{array}$ & $\begin{array}{l}21 \\
(7)\end{array}$ & $\begin{array}{l}0.33 \\
(0.14)\end{array}$ & $\begin{array}{l}0 \\
(0)\end{array}$ & $\begin{array}{l}373 \\
(96)\end{array}$ \\
\hline Chemical & 19 & $\begin{array}{l}50,191 \\
(17,293)\end{array}$ & $\begin{array}{l}582 \\
(302)\end{array}$ & $\begin{array}{l}0.18 \\
(0.08)\end{array}$ & $\begin{array}{l}0.12 \\
(0.01)\end{array}$ & $\begin{array}{l}3649 \\
(3101)\end{array}$ \\
\hline Rubber/plastic & 19 & $\begin{array}{l}12,550 \\
(2005)\end{array}$ & $\begin{array}{l}59 \\
(12)\end{array}$ & $\begin{array}{l}0.32 \\
(0.13)\end{array}$ & $\begin{array}{l}0.01 \\
(0.00)\end{array}$ & $\begin{array}{l}515 \\
(99)\end{array}$ \\
\hline Stone/mineral & 19 & $\begin{array}{l}15,626 \\
(2779)\end{array}$ & $\begin{array}{l}419 \\
(79)\end{array}$ & $\begin{array}{l}0.13 \\
(0.04)\end{array}$ & $\begin{array}{l}0.13 \\
(0.01)\end{array}$ & $\begin{array}{l}609 \\
(168)\end{array}$ \\
\hline Iron/steel & 19 & $\begin{array}{l}32,975 \\
(9956)\end{array}$ & $\begin{array}{l}1026 \\
(424)\end{array}$ & $\begin{array}{l}0.11 \\
(0.03)\end{array}$ & $\begin{array}{l}0.22 \\
(0.01)\end{array}$ & $\begin{array}{l}1290 \\
(225)\end{array}$ \\
\hline Fabricated metals & 19 & $\begin{array}{l}10,229 \\
(3435)\end{array}$ & $\begin{array}{l}34 \\
(20)\end{array}$ & $\begin{array}{l}0.37 \\
(0.15)\end{array}$ & $\begin{array}{l}0 \\
(0)\end{array}$ & $\begin{array}{l}3491 \\
(1625)\end{array}$ \\
\hline Machinery & 19 & $\begin{array}{l}69,621 \\
(18,361)\end{array}$ & $\begin{array}{l}120 \\
(36)\end{array}$ & $\begin{array}{l}0.35 \\
(0.15)\end{array}$ & $\begin{array}{l}0 \\
(0)\end{array}$ & $\begin{array}{l}890 \\
(336)\end{array}$ \\
\hline Electro & 19 & $\begin{array}{l}101,588 \\
(64,138)\end{array}$ & $\begin{array}{l}44 \\
(14)\end{array}$ & $\begin{array}{l}0.33 \\
(0.11)\end{array}$ & $\begin{array}{l}0.01 \\
(0.00)\end{array}$ & $\begin{array}{l}710 \\
(363)\end{array}$ \\
\hline Motor vehicles & 19 & $\begin{array}{l}135,385 \\
(53,975)\end{array}$ & $\begin{array}{l}164 \\
(27)\end{array}$ & $\begin{array}{l}0.28 \\
(0.10)\end{array}$ & $\begin{array}{l}0.03 \\
(0.00)\end{array}$ & $\begin{array}{l}1141 \\
(287)\end{array}$ \\
\hline
\end{tabular}

* Mean and standard deviations are for the years after the introduction of EU ETS.

\section{Empirical results}

This section consists of two parts. In the first part we display and discuss the results from the calculations of the environmental performance index. The second part includes the empirical convergence analysis, using the results from the first part.

\subsection{Environmental performance at the sector and aggregate level}

The results from using Eqs. (5) and (6) (and (8) for the aggregate manufacturing sector), i.e., the development over time of $E P$ and $I$, cumulative environmental performance, for each sector are presented in the form of box-plots in Figs. 3 and 4.

Fig. 3 shows that environmental performance tends to vary cyclically over time (the line within the boxes is the median over all sub-sectors).

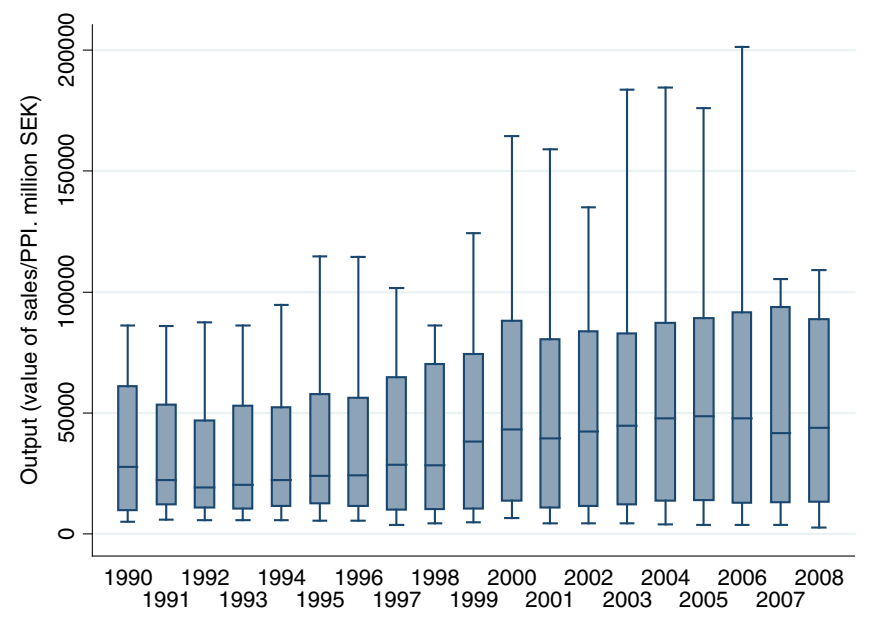

Fig. 1. Industrial sales (good output) in total Swedish manufacturing, 1990-2008.
One reason for this cyclical pattern may be that good output is more sensitive to business fluctuations than the bad output, $\mathrm{CO}_{2}$ emissions. This in turn may be because parts of the $\mathrm{CO}_{2}$ emissions tend to be fixed in the short run, for example the emissions generated by energy for heating. It is also evident from Fig. 3 that the variation within years (i.e., across sectors) is fairly large, which largely is a result of the use of differing production processes.

Furthermore, Fig. 4 reveals that the cumulative environmental performance has increased by approximately $60 \%$ over the time period under consideration. Again, on average the most significant improvements occurred after the turn of the century but also here we find significant differences across industrial sectors over the entire time period. Variation in intensity seems to have increased significantly around $1997 / 1998$, but after that it is fairly constant.

Finally, Fig. 5 displays the cumulative environmental performance for the entire manufacturing industry (geometric mean), both totally as well as decomposed into good and bad outputs. It is revealed in Fig. 5 that over the whole period we observe what has been called "relative decoupling" but not "absolute decoupling". ${ }^{8}$ In other words, good output has grown faster than the $\mathrm{CO}_{2}$ emissions, i.e., the emission intensity has fallen. Until approximately the year 2000, EP-good changed at about the same rate as EP-bad, thus leaving overall EP fairly constant. After the year 2000, however, we see evidence of an absolute decoupling, i.e., an improvement in both of these components. ${ }^{9}$ This means, not only have emissions per unit of good output fallen; absolute $\mathrm{CO}_{2}$ emissions have fallen. The EP and the cumulative EP index displayed above will be used in the empirical analysis below.

\footnotetext{
${ }^{8}$ Note that if we look the medians, as in Figs. 1 and 2, we see absolute decoupling, but we also saw that the distribution was very skewed, which is why the geometric mean results in Fig. 5 show relative decoupling.

${ }^{9}$ Remember from the definition of $E P$ that a decrease in EP-bad implies an increase in overall EP.
} 


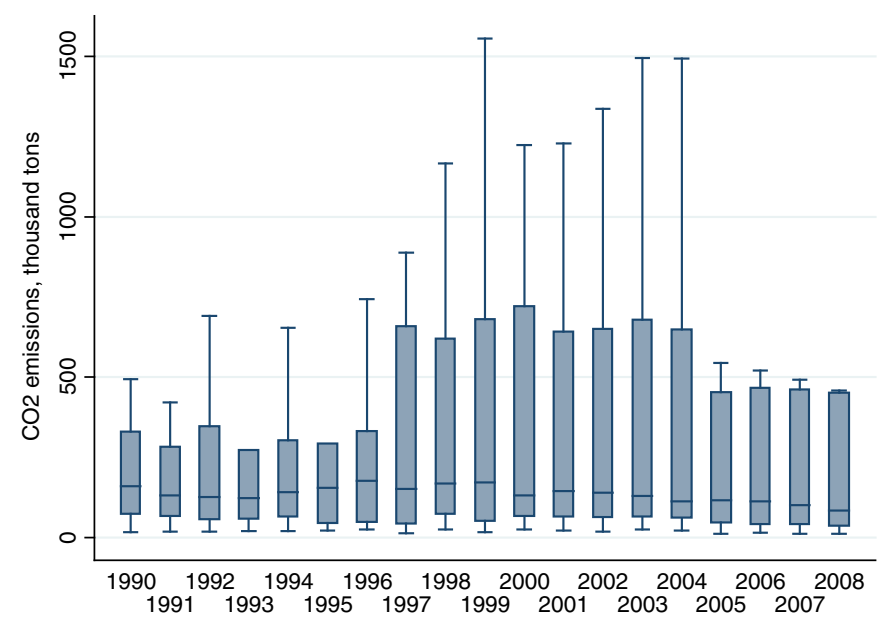

Fig. 2. $\mathrm{CO}_{2}$ emissions (bad output) in total Swedish manufacturing 1990-2008.

\subsection{Convergence analysis}

The main objective of this paper is to analyze the development over time of $\mathrm{CO}_{2}$ performance for the different sectors within the Swedish manufacturing industry, and investigate whether there is a convergence in emission intensity between these sectors. The basis for this analysis is Eq. (7). The dependent variable is thus the EP index for each sector, displayed in Fig. 3, whereas the key independent variable is the lagged cumulative EP, or inverse of emission intensity, presented in Fig. 4.

In order to check for robustness a number of different specifications of Eq. (7) and Eq. (8) with different types of restrictions concerning the independent variables, are estimated. In addition we have used both the fixed effect and random effects model and applied the Hausman test. The results from the Hausman test clearly reject the null hypothesis that the random effects model is consistent, which means that we here stick with the fixed effects model. ${ }^{10}$

Models 1-4 in Table 2 include no interaction effects, but with some alterations concerning the control variables. This means that in these models $\beta$, and hence the rate of convergence, is assumed to be the same for all sectors. In Models 5-6 interaction effects are included. In all of the specifications (1-6) we include fixed effects (for each sector). The sector characteristics that we include explicitly in the models are the sector-specific weighted average fossil fuel prices, whether a substantial share $(>10 \%)$ of the firms within a sector is part of EU ETS, and capital intensity.

If the fixed effects model outperforms the pooled model, while at the same time $\beta$ is negative, then we cannot reject the hypothesis that there is conditional $\beta$-convergence of $\mathrm{CO}_{2}$ performance in Swedish manufacturing. If, on the other hand, the fixed effects do not contribute to the model, we may or may not be able to reject absolute convergence. For being able to reject absolute convergence in the latter case the parameters that correspond to other sector characteristics have to be significantly different from zero.

In models 5 and 6 , including the interaction effects, we can test for equality between sectors concerning the speed of convergence. A statistically significant parameter for the interaction effect implies that " $\beta$ ", and hence the speed of convergence, depends on the particular sector characteristic, which in turn means that it in general differs between sectors.

The results from the estimations are presented in Table 2 . In summary, $\beta$ is overall significantly negative, thus pointing at convergence in $E P$ across industrial sectors. This result is robust with respect to different model specifications. The fixed effects and some of the other variables

\footnotetext{
${ }^{10}$ Considering that the data covers the whole manufacturing sector, and not a subsample, the fixed effects model is also for this reason adequate.
}



Fig. 3. Environmental $\left(\mathrm{CO}_{2}\right)$ performance $(E P)$ in Swedish manufacturing 1990-2008.

are also statistically significant, meaning that we can reject the hypothesis of absolute convergence. One important result is therefore that we cannot reject the hypothesis of conditional convergence, but reject absolute convergence. For instance, the results indicate that convergence is conditional on the average fossil fuel price. A higher fossil fuel price implies a higher $E P$, presumably since it then makes more economic sense for the industry to undertake $\mathrm{CO}_{2}$ abatement measures.

Concerning the speed of adjustment the results indicate that there are differences between sectors, and that these at least depend on differences in capital intensity. Industry sectors with relatively high capital intensities experience a lower speed of adjustment compared to less capital-intensive sectors. Furthermore, there seems to be no effect on $E P$ from participation in the EU ETS. Although this result could in part be explained by the relatively low allowance prices in the scheme during its first years, it should however be interpreted with care since there are very few observations since the introduction of EU ETS in 2005.

Concerning the significance of the interaction effect that involves capital intensity, this implies that the speed of convergence towards the steady-state level will be lower the higher is the capital intensity of the sector. This result is consistent with the notion that capitalintensive sectors have putty-clay technologies, which provide very little short-run flexibility in terms of factor input mixes as well as emission intensities. Fig. 6 provides an illustration of how " $\beta$ " (i.e., $\partial E P / \partial I$ ) develops over time for the different industry sectors as a result of changes

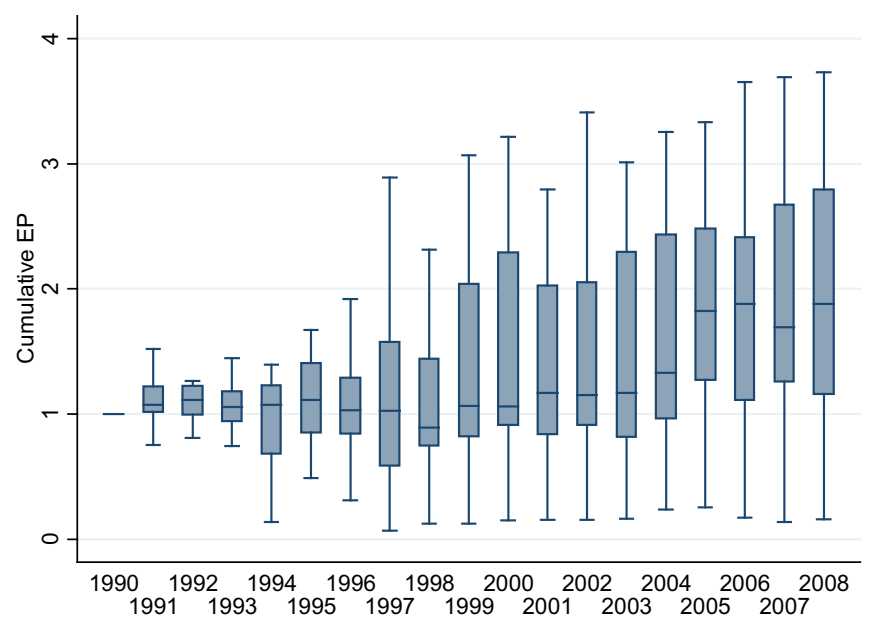

Fig. 4. Cumulative environmental performance (or the inverse of emission intensity, $I$ ). 


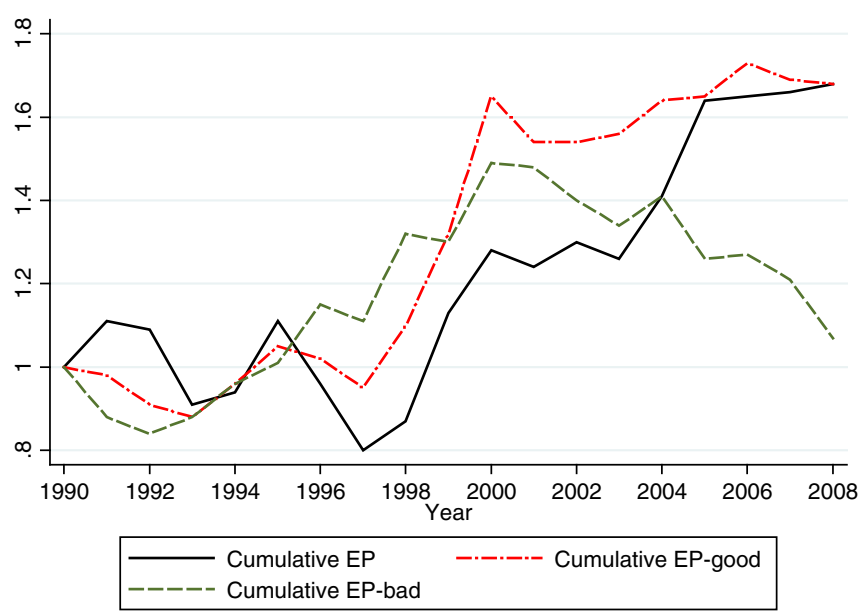

Fig. 5. Aggregate cumulative environmental performance or inverse of emission intensity, decomposed into "good" and "bad" (Index $1=1990)$.

in capital intensity (estimates based on Model 5). As can be seen there is a positive trend for all sectors, thus implying that the rate of $\mathrm{CO}_{2}$ performance convergence across industrial sectors has become lower over time. The explanation to this is that all of the industrial sectors have become increasingly capital intensive.

\section{Concluding comments}

In this paper we have provided a simple framework for the construction of an environmental performance index based on production theory. The theory provides an easy procedure in constructing an index that explicitly takes into account that firms produce good as well as bad outputs. This index is then used as the dependent variable in Solow growth-type regression analysis. The main advantages with this approach is: (1) it handles goods and bads explicitly, and (2) there is no simultaneity problem between emissions and GDP, which arises in the more standard emission per capita approach with, for instance, GDP as an explanatory variable.

The key empirical issue addressed in this study has been whether the growth rate of $\mathrm{CO}_{2}$ emission intensity in different industries in Sweden converges to a steady state, and whether they converge to the same steady state or not. The empirical motivation is two-fold. First of all, it provides knowledge of what we can expect concerning convergence at the global level. Second, a within-country analysis may be important and interesting on its own, especially concerning the consequences for different sectors of climate and energy policies.

Our findings can be summarized as follows. First, the environmental performance index we construct is simply the rate of change in the ratio of the inverse in emission intensity. For our purposes emission intensity is defined as the ratio of $\mathrm{CO}_{2}$ emission over production, the good output. Secondly, we show that by integrating this index we get the level of the index, or the accumulated performance. The latter is then used as the

Table 2

Regression results, $E P$ as the dependent variable. $t$-values within parenthesis.

\begin{tabular}{|c|c|c|c|c|c|c|}
\hline & Model 1 & Model 2 & Model 3 & Model 4 & Model 5 & Model 6 \\
\hline $\ln \left(I^{t-1}\right)$ & $\begin{array}{l}-0.25 \\
(-5.86)\end{array}$ & $\begin{array}{l}-0.26 \\
(-6.34)\end{array}$ & $\begin{array}{l}-0.41 \\
(-8.44)\end{array}$ & $\begin{array}{l}-0.40 \\
(-8.38)\end{array}$ & $\begin{array}{l}-1.44 \\
(-3.68)\end{array}$ & $\begin{array}{l}-1.36 \\
(-3.19)\end{array}$ \\
\hline $\ln \left(K^{t}\right)$ & & $\begin{array}{l}0.13 \\
(3.20)\end{array}$ & $\begin{array}{l}0.07 \\
(1.78)\end{array}$ & $\begin{array}{l}0.07 \\
(1.79)\end{array}$ & $\begin{array}{l}-0.50 \\
(-2.37)\end{array}$ & $\begin{array}{l}-0.55 \\
(-2.71)\end{array}$ \\
\hline $\ln \left(p^{t}\right)$ & & & $\begin{array}{l}0.33 \\
(5.18)\end{array}$ & $\begin{array}{l}0.34 \\
(5.00)\end{array}$ & & $\begin{array}{l}0.05 \\
(0.21)\end{array}$ \\
\hline EU ETS & & & & $\begin{array}{l}-0.02 \\
(-0.33)\end{array}$ & & $\begin{array}{l}-0.01 \\
(-0.21)\end{array}$ \\
\hline $\ln \left(I^{t-1}\right) \ln \left(K^{t}\right)$ & & & & & $\begin{array}{l}0.08 \\
(3.02)\end{array}$ & $\begin{array}{l}0.08 \\
(3.12)\end{array}$ \\
\hline $\ln \left(I^{t-1}\right) \ln \left(p^{t}\right)$ & & & & & & $\begin{array}{l}0.04 \\
(1.23)\end{array}$ \\
\hline d2 & $\begin{array}{l}0.32 \\
(3.23)\end{array}$ & $\begin{array}{l}0.24 \\
(2.41)\end{array}$ & $\begin{array}{l}0.29 \\
(3.02)\end{array}$ & $\begin{array}{l}0.28 \\
(2.87)\end{array}$ & $\begin{array}{l}0.27 \\
(2.77)\end{array}$ & $\begin{array}{l}0.39 \\
(3.47)\end{array}$ \\
\hline d3 & $\begin{array}{l}1.14 \\
(6.00)\end{array}$ & $\begin{array}{l}1.30 \\
(6.74)\end{array}$ & $\begin{array}{l}1.34 \\
(7.31)\end{array}$ & $\begin{array}{l}1.33 \\
(7.09)\end{array}$ & $\begin{array}{l}1.39 \\
(7.24)\end{array}$ & $\begin{array}{l}1.53 \\
(7.53)\end{array}$ \\
\hline $\mathrm{d} 4$ & $\begin{array}{l}0.64 \\
(4.99)\end{array}$ & $\begin{array}{l}0.82 \\
(5.95)\end{array}$ & $\begin{array}{l}0.69 \\
(5.14)\end{array}$ & $\begin{array}{l}0.68 \\
(4.93)\end{array}$ & $\begin{array}{l}0.85 \\
(6.24)\end{array}$ & $\begin{array}{l}0.82 \\
(5.05)\end{array}$ \\
\hline d5 & $\begin{array}{l}0.44 \\
(4.13)\end{array}$ & $\begin{array}{l}0.53 \\
(4.91)\end{array}$ & $\begin{array}{l}0.37 \\
(3.44)\end{array}$ & $\begin{array}{l}0.36 \\
(3.32)\end{array}$ & $\begin{array}{l}0.50 \\
(4.69)\end{array}$ & $\begin{array}{l}0.43 \\
(3.24)\end{array}$ \\
\hline d6 & $\begin{array}{l}0.83 \\
(5.64)\end{array}$ & $\begin{array}{l}0.93 \\
(6.31)\end{array}$ & $\begin{array}{l}0.93 \\
(6.65)\end{array}$ & $\begin{array}{l}0.92 \\
(6.29)\end{array}$ & $\begin{array}{l}0.93 \\
(6.41)\end{array}$ & $\begin{array}{l}1.05 \\
(6.02)\end{array}$ \\
\hline d7 & $\begin{array}{l}0.18 \\
(2.00)\end{array}$ & $\begin{array}{l}0.12 \\
(1.32)\end{array}$ & $\begin{array}{l}0.14 \\
(1.62)\end{array}$ & $\begin{array}{l}0.14 \\
(1.54)\end{array}$ & $\begin{array}{l}0.16 \\
(1.78)\end{array}$ & $\begin{array}{l}0.23 \\
(2.39)\end{array}$ \\
\hline d8 & $\begin{array}{l}0.92 \\
(5.87)\end{array}$ & $\begin{array}{l}0.99 \\
(6.37)\end{array}$ & $\begin{array}{l}1.09 \\
(7.36)\end{array}$ & $\begin{array}{l}1.09 \\
(7.14)\end{array}$ & $\begin{array}{l}0.96 \\
(6.27)\end{array}$ & $\begin{array}{l}1.20 \\
(6.42)\end{array}$ \\
\hline d9 & $\begin{array}{l}0.53 \\
(4.39)\end{array}$ & $\begin{array}{l}0.72 \\
(5.43)\end{array}$ & $\begin{array}{l}0.62 \\
(4.87)\end{array}$ & $\begin{array}{l}0.61 \\
(4.72)\end{array}$ & $\begin{array}{l}0.74 \\
(5.64)\end{array}$ & $\begin{array}{l}0.74 \\
(4.78)\end{array}$ \\
\hline $\mathrm{d} 10$ & $\begin{array}{l}0.16 \\
(1.79)\end{array}$ & $\begin{array}{l}0.09 \\
(0.98)\end{array}$ & $\begin{array}{l}-0.02 \\
(-0.27)\end{array}$ & $\begin{array}{l}-0.03 \\
(-0.35)\end{array}$ & $\begin{array}{l}0.15 \\
(1.60)\end{array}$ & $\begin{array}{l}0.09 \\
(0.84)\end{array}$ \\
\hline d11 & $\begin{array}{l}0.51 \\
(4.38)\end{array}$ & $\begin{array}{l}0.66 \\
(5.34)\end{array}$ & $\begin{array}{l}0.50 \\
(4.14)\end{array}$ & $\begin{array}{l}0.50 \\
(4.03)\end{array}$ & $\begin{array}{l}0.66 \\
(5.39)\end{array}$ & $\begin{array}{l}0.60 \\
(4.04)\end{array}$ \\
\hline $\mathrm{d} 12$ & $\begin{array}{l}0.09 \\
(1.02)\end{array}$ & $\begin{array}{l}0.19 \\
(2.06)\end{array}$ & $\begin{array}{l}0.08 \\
(0.92)\end{array}$ & $\begin{array}{l}0.08 \\
(0.94)\end{array}$ & $\begin{array}{l}0.09 \\
(0.91)\end{array}$ & $\begin{array}{l}0.00 \\
(0.01)\end{array}$ \\
\hline $\mathrm{d} 13$ & $\begin{array}{l}0.23 \\
(2.46)\end{array}$ & $\begin{array}{l}0.38 \\
(3.70)\end{array}$ & $\begin{array}{l}0.07 \\
(0.65)\end{array}$ & $\begin{array}{l}0.07 \\
(0.57)\end{array}$ & $\begin{array}{l}0.28 \\
(2.61)\end{array}$ & $\begin{array}{l}0.04 \\
(0.31)\end{array}$ \\
\hline $\mathrm{d} 14$ & $\begin{array}{l}0.77 \\
(5.45)\end{array}$ & $\begin{array}{l}0.87 \\
(6.14)\end{array}$ & $\begin{array}{l}0.76 \\
(5.55)\end{array}$ & $\begin{array}{l}0.75 \\
(5.30)\end{array}$ & $\begin{array}{l}0.88 \\
(6.28)\end{array}$ & $\begin{array}{l}0.86 \\
(5.31)\end{array}$ \\
\hline Cons & $\begin{array}{l}1.37 \\
(5.42)\end{array}$ & $\begin{array}{l}-0.29 \\
(-0.50)\end{array}$ & $\begin{array}{l}3.69 \\
(3.92)\end{array}$ & $\begin{array}{l}3.68 \\
(3.90)\end{array}$ & $\begin{array}{l}8.46 \\
(2.87)\end{array}$ & $\begin{array}{l}10.73 \\
(3.23)\end{array}$ \\
\hline Adj $R^{2}$ & 0.15 & 0.13 & 0.22 & 0.22 & 0.16 & 0.25 \\
\hline$N$ & 252 & 252 & 252 & 252 & 252 & 252 \\
\hline
\end{tabular}




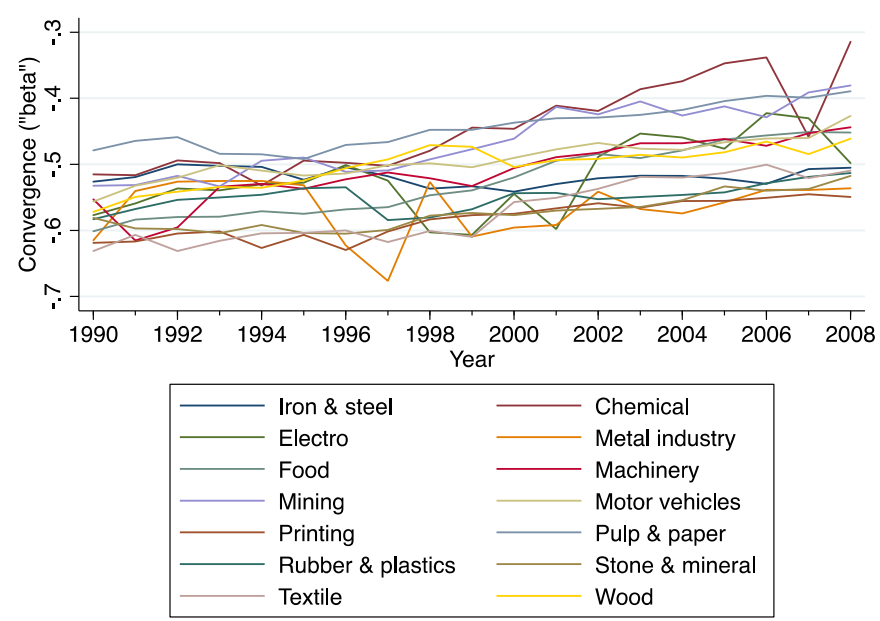

Fig. 6. $\beta$-convergence of environmental performance. $\partial E P / \partial I=\beta+\gamma K=-1.44+$ $0.08 \cdot K$.

main independent variable in the regression analysis and corresponds to the (lagged) level of emissions in the more commonly used emission per capita approach. Concerning the empirical part we tested both the unconditional and conditional $\beta$-convergence hypothesis. Here we find strong evidence in support of conditional $\beta$-convergence in $\mathrm{CO}_{2}$ performance among the industrial sectors in Sweden. Moreover, we also found that EU ETS participation, measured as the share of firms included in the EU ETS, did not have any significant effect on the convergence rate, or the steady state. ${ }^{11}$ However, the results also show that higher fossil fuel prices tend to result in improved $\mathrm{CO}_{2}$ performance in the Swedish industrial sectors.

Furthermore, by using interaction terms the results show that the rate of convergence varies significantly with capital intensity, in the sense that the higher the capital intensity is, the lower is the convergence rate to the steady state. In other words, sectors with different capital intensities will not only converge to different steady states, but also do this at different rates. The capital intensities of the Swedish industrial sectors have increased over time, thus resulting in slower speeds of convergence. This provides a micro-level illustration of the important role of capital turnover in achieving a cost-effective transition towards lower emissions.

Although one should be careful in pointing out that our results apply only to the case of Swedish industry, the role of capital intensity for emissions convergence is likely to be valid in other countries as well. Countries with relatively high shares of capital-intensive industries may experience slower emissions convergence. This may also have important implications for the future dynamics of future $\mathrm{CO}_{2}$ emissions and abatement efforts at the global level. Many scientists claim that the atmospheric stabilization of the climate requires a certain amount of urgency, including relatively rapid abatement efforts in both the developed and the developing world. If the time allowed for the transition to a lower emission path is narrowed, the capital stock will need to be replaced before it wears out. As a result, overall abatement costs will increase, and in the presence of slow convergence patterns multilateral agreements may be more difficult to achieve. The fast growth of some Asian and African countries, considerably increasing their capital intensities, may add to these difficulties. ${ }^{12}$

\footnotetext{
11 This corroborates to some degree Lundgren et al. (2013), who find that the EU ETS have not had a significant effect on environmentally sensitive productivity in the Swedish pulp and paper industry. Their conclusion is that the $\mathrm{CO}_{2}$ allowance price has probably been too low to give incentives enough to impact environmental and/or economic performance.

12 Capital intensity may also be one contributing explanation as to why many previous studies seem to reject the presence of global $\mathrm{CO}_{2}$ convergence, but at the same time not reject convergence among specific groups of countries (Pettersson et al., 2014).
}

Most analyses, so far, concerning convergence of $\mathrm{CO}_{2}$ emissions, have focused on per capita emissions. One reason for this is that much of the policy discussion has centered on emission obligations of an egalitarian-type of rule, such as equal emissions per capita. If emissions globally tend to converge to the same steady state, such an egalitarian rule could also be efficient. However, as pointed out in Pettersson et al. (2014), the empirical support for such an egalitarian rule is weak. There is simply meager evidence of carbon convergence in per capita emissions at the global level, implying in turn that policies that impose equal per capita emissions are likely to generate significant redistributional impacts and significant transfers of wealth. It is in light of this the approach taken here, looking specifically at emission intensity, may be interesting. Nevertheless, our results indicate that different industrial sectors converge to different steady states, and that capitalintensive sectors converge more slowly. In other words, similar distributional problems will appear with an allocation rule based on equal emission intensities (rather than per capita allocation).

The results from this paper further suggest that future research should increasingly address the structural characteristics of countries (e.g., natural resource endowments, industry structure, geographical characteristics), and their role influencing future emission dynamics. Our work focuses only on Sweden, and similar studies on other developed and developing countries would be useful. Moreover, the environmental index approach adopted in this paper can also be employed both at the global and the country level, and be generalized to cases with several bad (and good) outputs.

\section{Appendix A. Supplementary data}

Supplementary data to this article can be found online at http://dx. doi.org/10.1016/j.eneco.2015.07.004.

\section{References}

Aldy, J.E., 2006. Per capita carbon dioxide emissions: convergence or divergence? Environ. Resour. Econ. 33 (4), 533-555.

Aldy, J.E., 2007. Divergence in state-level per capita carbon dioxide emissions. Land Econ. 83 (3), 353-369.

Baldwin, J.G., Sue Wing, I., 2013. The spatiotemporal evolution of U.S. carbon dioxide emissions: stylized facts and implications for climate policy. J. Reg. Sci. 53 (4), 672-689.

Barassi, M.R., Cole, M.A., Elliott, R.J.R., 2008. Stochastic divergence or convergence of per capita carbon dioxide emissions: re-examining the evidence. Environ. Resour. Econ. 40 (1), 121-137.

Brännlund, R., Lundgren, T., Marklund, P.-O., 2014. Carbon intensity in production and the effects of climate policy-evidence from Swedish industry. Energy Policy 61, 844-857.

Brock, W.A., Taylor, M.S., 2010. The green Solow model. J. Econ. Growth 15 (2), 127-153. Burnett, W.J., 2013. Club convergence and clustering of U.S. energy-related $\mathrm{CO}_{2}$ emissions Paper presented at the Agricultural and Applied Economics Association 2013 Annual Meeting, August 4-6, Washington, DC.

Camarero, M., Picazo-Tadeo, A.J., Tamarit, C., 2013. Are the determinants of $\mathrm{CO}_{2}$ emissions converging among OECD countries? Econ. Lett. 118, 159-162.

Ezcurra, R., 2007. Is there cross-country convergence in carbon dioxide emissions? Energy Policy 35 (2), 1363-1372.

Färe, R., Grosskopf, S., Hernandez-Sancho, F., 2003. Environmental performance: an index number approach. Resour. Energy Econ. 26 (4), 343-352.

Färe, R., Grosskopf, S., Pasurka Jr., C.A., 2006. Social Responsibility: U.S. Power Plants 1985-1998. J. Prod. Anal. 26 (3), 259-267.

Färe, R., Grosskopf, S., Lundgren, T., Marklund, P.-O., Zhou, W., 2014. Pollution generating technologies and environmental efficiency. J. Chin. Econ. Bus. Stud. 12 (3), 233-251.

Frankel, J., 2007. Formulas for Quantitative Emission Targets. Faculty Research Working Paper Series RWP07-011. Harvard University, Cambridge.

Huang, B., Meng, L., 2013. Convergence of per capita carbon dioxide emissions in urban China: a spatial temporal perspective. Appl. Geogr. 40, 21-29.

Liddle, B., 2009. Electricity intensity convergence in IEA/OECD countries: aggregated and sectorial analysis. Energy Policy 27, 1470-1478.

Lundgren, T., Marklund, P.-O., 2014. Climate policy, environmental performance, and profits. J. Prod. Anal. (forthcoming).

Lundgren, T., Marklund, P.-O., Samakovlis, E., Zhou, W., 2013. Carbon Prices and Incentives for Technological Development. Working Paper 2013:4. Centre for Environmental and Resource Economics (CERE), Umeå, Sweden.

Mattoo, A., Subramanian, A., 2010. Equity in Climate Change. An Analytical Review. Policy Research Working Paper 5383. The World Bank, Washington, DC. 
Miketa, A., Mulder, P., 2005. Energy productivity across developed and developing countries in 10 manufacturing sectors: patterns of growth and convergence. Energy Econ. 27 (3), 429-453.

Moutinho, V., Robaina-Alves, M., Mota, J., 2014. Carbon dioxide emissions intensity of Portugese industry and energy sectors: a convergence analysis and econometric approach. Renew. Sust. Energ. Rev. 40, 438-449.

Mulder, P., de Groot, H.L.F., 2012. Structural change and convergence of energy intensity across OECD countries, 1970-2005. Energy Econ. 34, 95-104.

Never, B., Betx, J., 2014. Comparing climate policy performance of emerging countries. World Dev. 59, 1-15.

Nourry, M., 2009. Re-examining the empirical evidence for stochastic convergence of two air pollutants with a pair-wise approach. Environ. Resour. Econ. 44 (4), 555-570.

Ordás Criado, C., Valente, S., Stengos, T., 2011. Growth and pollution convergence: theory and practice. J. Environ. Econ. Manag. 62, 199-214.

Panopoulou, E., Pantelidis, T., 2009. Club convergence in carbon dioxide emissions. Environ. Resour. Econ. 44 (1), 47-70.

Pettersson, F., Maddison, D., Acar, S., Söderholm, P., 2014. Convergence of carbon dioxide emissions: a review of the literature. Int. Rev. Environ. Resour. Econ. 7 (2), 141-178.
Quah, D.T., 1993. Galton's fallacy and tests of the convergence hypothesis. Scand. J. Econ. 95 (4), 427-443.

Solow, R., 1956. A contribution to the theory of economic growth. Q. J. Econ. 70 (1), 65-94.

Strazicich, M.C., List, J.A., 2003. Are $\mathrm{CO}_{2}$ emission levels converging among industrial countries? Environ. Resour. Econ. 24 (3), 263-271.

Van Nguyen, P., 2005. Distribution dynamics of $\mathrm{CO}_{2}$ emissions. Environ. Resour. Econ. 32 (4), 495-508.

Wang, J., Zhang, K., 2014. Convergence of carbon dioxide emissions in different sectors in China. Energy 65, 605-611.

Westerlund, J., Basher, S.A., 2008. Testing for convergence in carbon dioxide emissions using a century of panel data. Environ. Resour. Econ. 40 (1), 109-120.

Yavuz, N.C., Yilanci, V., 2013. Convergence in per capita carbon dioxide emissions among G7 countries: a TAR panel unit root approach. Environ. Resour. Econ. 54 (2), 283-291.

Zhao, X., 2014. Three Essays on Investigating Province-Level Carbon Dioxide Emissions in China Ph.D. Dissertation West Virginia University, USA. 